\title{
ОРГАНЫ ВНЕСУДЕБНОГО РАССМОТРЕНИЯ ЖАЛОБ ГРАЖДАНСКИХ СЛУЖАЩИХ ВЕЛИКОБРИТАНИИ И США
}

\begin{abstract}
Аннотация: Объект исследования статьи составляет совокупность материальных и процессуальных норм права, регулирующих деятельность органов, осуществляющих внесудебное рассмотрение жалоб гражданских служащих Великобритании и США, регламентирующих правовой статус служащих, а также теоретические положения проведенных научных исследований, посвященных изучению гражданской службы.

Целью работы является выявление особенностей правового регулирования внесудебного рассмотрения жалоб гражданских служащчи в Великобритании и США, статуса органов его осуществляющих, а также проиессуальной специффики внесудебной защиты прав служащих.

Методологические основы исследования составляют общенаучные (анализ и синтез, сравнение, описание, обобщение, классификация, дедукция и индукиия) и частно-научные (формально-юридический, сравнительноправовой) методы познания.

Результатом проведенного исследования является выявление специфики моделей внесудебной защчиты гражданских служащчх в странах англосаксонской правовой семьи в соотношении с особенностями национального правового регулирования.

Результаты работы могут быть применены в совершенствовании нормативной базы, а также правовых механизмов внесудебной защиты прав гражданских служащих в Российской Федерации.

Выводы работы демонстрируют принциииально различные, но эффективные подходы к построению модели внесудебной защиты прав гражданских служащчи в форме рассмотрения их жалоб и вынесения по ним решений. Ключевые слова: Юриспруденция, гражданская, служба, Великобритания, США, жалобы, несудебное, рассмотрение, органы, проиесс
\end{abstract}

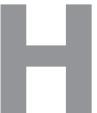

есудебное рассмотрение жалоб британских и американских гражданских служащих осуществляется административными органами, обладающими квазисудебными полномочиями. В Великобритании это Комиссия по делам гражданской службы (CivilServiceCommission), Консультационная, примирительная и арбитражная служба ACAS, а также Апелляционная комиссия гражданской службы (CivilServiceAppealBoard).

Комиссия по делам гражданской службы является коллегиальным органом, основным назначением которого является управление в сфере кадровой политики. Апелляционная комиссия гражданской службы - коллегиальный орган, подотчетный Кабинету министров, состоящий из трех членов, назначаемых Кабинетом, среди которых представлены как департаменты и агентства-наниматели, так и профсоюз ${ }^{1}$. Консультационная, примирительная и арбитражная служба ACAS, как следует из названия, специализируется на неформальном разрешении служебных споров.

Чтобы сориентироваться в данной системе, следует более детально изучить те основания, на которых подается жалоба в соответствующий орган.

\footnotetext{
${ }^{1}$ 12.1.7 Civil Service Management Code.
}

Согласно Закону о конституционной реформе и управлении 2010 г. $^{2}$ и Кодексу управления гражданской службой ${ }^{3}$, Комиссия обладает квазисудебной юрисдикцией по вопросам, относящимся к регулированию Кодекса гражданской службы ${ }^{4}$ В компетенцию Комиссии по делам гражданской службы входит рассмотрение жалоб о противоречащих этическим нормам Кодекса гражданской службы действиях со стороны руководства либо сослуживцев. Таким образом, Комиссия осуществляет контроль за исполнением этических норм, обязанность соблюдать и обеспечивать соблюдение которых вменена главам департаментов и агентств.

В юрисдикцию Апелляционной комиссии, согласно Кодексу управления гражданской службой, входит рассмотрение жалобна несправедливое, по мнению, служащего, увольнение, невыплату или недоплату жалования либо пенсий, необоснованные запреты на участие в политических мероприятиях (12.1.7 Кодекса управления гражданской службой). Апелляционная

\footnotetext{
${ }^{2}$ P.1, C.1, Sec.2(4) Constitutional Reform and Governance Act 2010 The Stationery Office Limited, 2010.

${ }^{3} \mathrm{http}$ ://www.civilservice.gov.uk/about/resources/civil-service-management-code

${ }^{4}$ http://www.civilservice.gov.uk/about/values/
} 


\section{Право и политика $2(158) \cdot 2013$}

комиссия представляется основным органом несудебной защиты прав служащих, напрямую не относящихся к сфере служебной этики.

По общему правилу, согласно практическому дисциплинарному кодексу ${ }^{5}$, четких процессуальных полномочий касательно оспариваемого действия нет ни у Комиссии по делам гражданской службы, ни у Апелляционной комиссии. Эти вопросы решаются руководством департаментов и агентств по договоренности с соответствующей Комиссией.

Консультационная, примирительная и арбитражная служба ACAS, хотя и не принимает жалоб непосредственно, играет существенную роль в обеспечении их рассмотрения. Решения, выносимые в результате деятельности Службы не являются обязательными к исполнению юридически, однако они учитываются, если дело доходит до судебного разбирательства. Следует отметить, что вынесение обязывающего решения не является целью деятельности Службы. Ее целью является создание условий для разрешения спора в порядке переговоров.

Рассмотрим процедуры подачи жалоб. Изначально жалоба в Комиссию по делам гражданской службы, согласно параграфам 16-18 Кодекса гражданской службы, подается либо руководству, либо особому должностному лицу данного департамента или агентства, в обязанности которого входит обеспечение соблюдения профессиональной этики. В случае отказа в принятии решения либо в принятии неудовлетворительного решения по данной жалобе, а также в случае острой необходимости, либо ввиду недоступности руководства департамента или агентства, служащий имеет право обратиться напрямую в Комиссию по делам гражданской службы (12.1.6 Кодекса управления гражданской службой).

В отличие от подачи жалобы в Комиссию гражданской службы, жалобы в Апелляционную комиссию, по общему правилу, направляются напрямую. Особенностью Апелляционной комиссии является, несмотря на обязательность выносимых ею решений, существенная свобода от излишнего формализма процедур. Так, Комиссия предлагает четыре различных способа рассмотрения жалобы, включая как очный, требующий физического присутствия сторон, либо их представителей ${ }^{6}$, так и заочный, осуществляемый на основании документов, присылаемых сторонами, а также установленные в последние годы формы видеоконференции, либо телеконференции, осуществляемые при помощи технических средств аудиовизуальной передачи информации. Следует обратить внимание на тот факт, что

\footnotetext{
${ }^{5}$ Code of Practice Discipline and Grievance Procedures, Blackwell, TSO 2009.
}

${ }^{6}$ Face to Face hearing. в современной практике жалобы на неправомерное увольнение рассматриваются, в основном, трудовыми судами (EmploymentTribunals), а не Апелляционной комиссией ${ }^{7}$.

Служба ACAS участвует в процессе рассмотрения жалоб служащих несколькими способами. Во-первых, она издает практический дисциплинарный Кодекс ${ }^{8}$, который обеспечивается судебной практикой. Во-вторых, Служба осуществляет авторитетное сопровождение несудебного разрешения споров между служащими и департаментами и агентствами-нанимателями. Служба предоставляет услуги консультирования сторонам, участвующим в процессе разрешения спора, а также выполняет функции посредника и арбитра. Решения Службы не являются обязательными к исполнению, однако учитываются в судах.

Британская система несудебного рассмотрения жалоб представляется весьма гибкой в выборе возможностей неформального разрешения споров. Нарушения наиболее фундаментальных для гражданской службы норм (таких, как этический Кодекс гражданской службы), а также норм, закрепляющих основные гарантии гражданских служащих (гарантии справедливого вознаграждения, защиты от неправомерного увольнения и ограничения прав), рассматриваются в административном или судебном порядке.

Жалобы как таковые, как правило, рассматриваются либо внутри департаментов и агентств, либо посредством медиации при участии представителей сторон (со стороны служащего часто эту роль играет профсоюз). Жалобы о нарушении прав служащих на справедливое вознаграждение и выплату пенсий, а также на участие в политической деятельности в административном порядке рассматривает Апелляционная комиссия. Комиссия по делам гражданской службы играет роль высшей инстанции по вопросам профессиональной этики, в то время как суды разрешают иные вопросы нарушения прав служащих.

Характерной чертой рассмотрения жалоб служащих представляется низкая степень формализации административного процесса.

В США жалобы гражданских служащих рассматриваются Комитетом по защите системы заслуг (MeritSystemProtectionBoard) напрямую, или Комиссией по обеспечению равных возможностей при трудоустройстве (EqualEmploymentOpportunityCommission, EEOC).

Объем полномочий Комитета по защите системы заслуг закреплен в секции 1214 главы 5 Свода законов США9 В основном, Комитет сосредоточил в своих руках процессуальные полномочия, направленные на обеспечение функционирования гражданской службы в соответствии с

\footnotetext{
${ }^{7}$ http://www.civilserviceappealboard.gov.uk/

${ }^{8} \mathrm{http}: / /$ www.acas.org.uk/media/pdf/k/b/Acas_Code_of_Practice_1_ on_disciplinary_and_grievance_procedures-accessible-versionJul-2012.pdf

${ }_{9} 5$ USC par. 1214, http://www.law.cornell.edu/uscode/text/5/1214
} 
Государственные институты и правовые системы

установленными законодательством принципами. Данные полномочия включают в себя направление повесток, требующих явки и дачи свидетельских показаний, истребование протоколов допросов свидетелей и их письменных показаний. Основное поле деятельности Основными задачами Комитета по защите системы заслуг являются адъюдикация ${ }^{10}$ вопросов, связанных с нарушением законодательства, регулирующего принципы системы заслуг и их применение в кадровой практике публичных институтов США. Неподчинение законным требованиям Комитета в отсутствии веских оснований влечет за собой судебные санкции за неуважение к Суду. Комитет имеет право давать руководителю Службы управления персоналом рекомендаций во время процедуры адъюдикации, либо расследования. По просьбе Кабинета особого советника Комитет может требовать защиты свидетелей. Комитет по защите системы заслуг действует по двум направлениям - Апелляционной юрисдикичи (AppellateJurisdiction) и Основной юрисдикичи (OriginalJurisdiction).Споры основной юрисдикции рассматриваются в отделениях Комитета. Основная юрисдикция подразумевает первичное рассмотрение дел, относящихся к нарушению принципов системы заслуг и случаев запрещенной кадровой практики. Жалобы в рамках основной юрисдикции, как правило, изначально проходят через Управление особого советника. В порядке Основной юрисдикции проходит первичное рассмотрение дел, относящихся к нарушению принципов системы заслуг и случаев запрещенной кадровой практики. Жалобы в рамках основной юрисдикции, как правило, изначально проходят через Управление особого советника.

Споры апелляционной юрисдикции рассматриваются административным судьей при Комитете, который выносит первоначальное решение. В отсутствие заявлений о пересмотре от сторон, это решение вступает в силу через 35 дней после его вынесения.

Апелляционная юрисдикция закрепляется Законом о реформе федеральной службы 1978г. ${ }^{11}$ Она включает в себя право рассматривать апелляции на различные действия агентств, включая апелляции на решения по делам, рассмотренным расформированной в Комиссией по делам гражданской службы (CivilServiceCommission) до принятия Закона 1978 г.

Управление особого советника является федеральным независимым агентством, осуществляющим проведение расследований и инициирующим административную процедуру в порядке, установленном законом. Согласно

\footnotetext{
${ }^{10}$ Согласно секции 2 Закона об административной процедуре 1946 г.P.L. 79-404, (60 S 237), адъюдикация определяется как процедура вынесения агентством решения, не относящегося к нормотворчеству.

${ }^{11}$ Federal service Reform Act 1978 P.L 95-454, 92 Stat. 111.
}

Закону о реформе федеральной службы 1978г. и Закону о защите информаторов 1989г. ${ }^{12}$, основной задачей Управления является обеспечение сохранности системы заслуг путем защиты прав федеральных служащих и лиц, поступающих на публичную службу от запрещенной кадровой практики.

Управление особого советника как орган управления гражданской службой выполняет функции контроля и имеет широкие полномочия в сфере обнаружения и расследования случаев запрещенной кадровой практики, однако не обладает прямыми полномочиями для наложения форм ответственности, предотвращения, и прекращения действий, связанных с незаконной кадровой практикой (ProhibitedPersonnelPractices, или PPPs). При этом Управление имеет право передавать дела доказанных случаев кадровой практики в Комитет по защите системы заслуг, которая такими полномочиями обладает.

Комиссия по равным условиям найма является органом, ответственным за обеспечение исполнения специализированного антидискриминационного законодательства $^{13}$, в то время как Комитет по защите системы заслуг специализируется на нарушениях принципов системы заслуг в рамках гражданской службы. В его компетенцию входит рассмотрение жалоб на дискриминацию по признаку пола, возраста, цвета кожи, национальности, вероисповедания, инвалидности, болезни и по иным признакам, а также жалобы на репрессивные действия со стороны руководства против сотрудников, противодействующих такой дискриминации.

Рассмотрим процедуру подачи жалобы. Жалоба по установленной форме направляется в Отдел рассмотрения жалоб (Complaintsexaminingunit) Управления особого советника $^{14}$. Лицо, подающее жалобу, в пятнадцатидневный срок получает один или несколько вариантов ответа. Письмо, подтверждающее получение жалобы и объясняющее порядок, в котором она будет рассматриваться, отчет о ходе решения проблемы лица, если его жалоба была принята и находится в процессе рассмотрения. После детального рассмотрения жалобы, Отдел передает имеющие обоснованные заявления в одно из четырех подразделений Отдела расследования и предъявления исков (InvestigationandProsecutionDivision), расположенных в Вашингтоне, Далласе, Детройте и Сан Франциско. Отдел проводит расследование на основании полученной

\footnotetext{
${ }^{12}$ Whistleblower Protection Act 1989 P.L. 101-12, 103 Stat. 16.

${ }^{13}$ Civil Rights Act of 1964 Pub. L. 88-352, Equal Pay Act of 1963 Pub. L. 88-38, Age Discrimination in Employment Act of 1967 Pub. L. 90-202, Americans with Disabilities Act of 1990 Pub. L. 101-336, Civil Rights Act of 196442 U.S.C. 2000e-5, Rehabilitation Act of 1973 Pub. L. 93-112, Genetic Information Nondiscrimination Act of 2008Pub.L. 110-233, 122 Stat. 881.

${ }^{14} \mathrm{http}: / /$ www.osc.gov/pppNext1.htm
} 


\section{Право и политика 2 (158) • 2013}

жалобы, включающее в себя просмотр записей, относящихся к делу, опрос свидетелей. В случае необходимости, производится правовая проверка (legalreview) факта установления Отделом случая нарушения правовых норм и необходимости применения правозащитных мер. Если такие нарушения выявлены, дело отправляется в Комитет по защите системы заслуг.

В качестве альтернативы, после рассмотрения заявления Отделом рассмотрения жалоб Управление особого советника в ряде случаев предлагает посредничество в переговорах. Процедура примирения сторон производится подразделением альтернативного решения разногласий (AlternativeDisputeResolutionUnit) при условии согласия обеих сторон с целью достижения обоюдно согласованного решения проблемы.

Комитет по защите системы заслуг и Комиссия по обеспечению равных возможностей отчасти пересекаются в сфере своей компетенции. В некоторых случаях возникают юрисдикционные конфликты - в частности, по делам о дискриминации, подпадающим под смешанную юрисдикцию. Жалобы, относящиеся к смешанной юрисдикции, называются «смешанными» (Mixed Cases). Смешанные жалобы или апелляции (MixedcaseComplaint, orMixedCaseAppeal ${ }^{15}$ ) производятся в случае, если его подает служащий агентства, находящегося в юрисдикции Комитета по защите системы заслуг, но апеллирует к правовым нормам, регулирующим деятельность Комиссии по равным условиям.

Если Комитет и Комиссия не придут к согласию, дело будет передано в Особую комиссию (Specialpanel) ${ }^{16}$ для принятия окончательного решения. Особая комиссия - коллегиальный орган, состоящий из Председателя, назначаемого президентом, члена Комитета по защите системы заслуг, назначаемого председателем данного Комитета и одного члена Комиссии по равному доступу, назначаемого, соответственно, председателем Комиссии. Жалоба по поводу дискриминации, не подотчетная Комитету, рассматривается по внутренним каналам агентства и через Комиссию.

Таким образом, американская система несудебного рассмотрения жалоб служащих предполагает четкое законодательное закрепление административных процедур. Взаимодействие Управления особого советника и Комиссии по защите системы заслуг образует правозащитный механизм, схожий с взаимодействием прокуратуры и суда. Компетенция органов, осуществляющих

\footnotetext{
${ }^{15}$ имеют процессуальные различия. MixedCaseComplaint направляется в MSPB по вынесении решения на основании внутреннего расследования Агентства. MixedCaseAppeal осуществляется при непосредственной подаче заявления после неблагоприятного (adverse) действия со стороны агентства.

${ }^{16} \mathrm{http}: / /$ www.mspb.gov/about/jurisdiction.htm
}

несудебную защиту прав служащих, законодательно разделена более жестко. Комитет по защите системы заслуг и Управление особого советника работают строго на основании факта нарушения принципов системы заслуг и случаев запрещенной кадровой практики, в то время как Комиссия по обеспечению равных возможностей специализируется на нарушении антидискриминационного законодательства. Однако, в силу наличия положений о защите от дискриминации в принципах системы заслуг и списке запрещенных кадровых практик, могут возникать юрисдикционные конфликты.

По своему статусу органы несудебного рассмотрения жалоб Великобритании и США имеют как сходства, так и различия. Комиссия по делам гражданской службы и Апелляционная комиссия Великобритании выполняют квазисудебные административные функции. Их можно соотнести с Комитетом по защите системы заслуг и Комиссией по обеспечению равных возможностей в США, однако разница в компетенции представляется существенной. Британские органы, обладающие квазисудебными полномочиями, в неформализованном рассматривают, в основном, нарушение этических стандартов и довольно узкую категорию служебных прав лиц, находящихся на гражданской службе, оставляя «последнее слово» за судами. В США Комиссии обладают более широким спектром процессуальных полномочий, а процедура рассмотрения жалоб куда более формализована, и по своей сложности приближается к судебному процессу с судом и «прокурором».

С другой стороны, в Британии более развитой представляется процедура урегулирования служебных споров в форме переговоров. Служба АСАSосуществляет как регламентацию процедур таких переговоров, так и предоставляет все условия для такого мирного урегулирования. В США схожую функцию, в меньшем объеме, осуществляет отдел альтернативного разрешения споров Управления особого советника.

Что касается правового регулирования деятельности органов несудебного рассмотрения жалоб, в США оно осуществляется на уровне законодательства с четко прописанной процессуальной составляющей. В Великобритании эта сфера регулируется актами делегированного законодательства, а также рекомендательными документами, которые не являются обязательными сами по себе, но обеспечиваются судебными решениями.

Представляется, что британская система максимально дистанцируется от формализованного судебного процесса, позволяя рассматривать жалобы гражданских служащих быстро и неформально. Административная и судебная процедуры используются при невозможности неформального разрешения спора. В случае США, 
Государственные институты и правовые системы

напротив, несудебное рассмотрение жалоб отличается четкой регламентацией процедур общеобязательными нормами права, а неформальные процедуры предоставляются лишь в качестве альтернативы.

\section{Библиография $\backslash$ References:}

1. Administrative Procedure Act 1946 г. P.L. 79-404, 60 S 237;

2. Age Discrimination in Employment Act of 1967 Pub. L. 90-202;

3. Americans with Disabilities Act of 1990 Pub. L. 101-336;

4. Civil Rights Act of 196442 U.S.C. 2000e-5;

5. Constitutional Reform and Governance Act 2010 The Stationery Office Limited, 2010. P.1, C.1, Sec.2(4);

6. Equal Pay Act of 1963 Pub. L. 88-38;

7. Federal service Reform Act 1978 P.L 95-454, 92 Stat. 1111;
8. Genetic Information Nondiscrimination Act of 2008 Pub.L. 110-233, 122 Stat. 881;

9. Rehabilitation Act of 1973 Pub. L. 93-112;

10. Whistleblower Protection Act 1989 P.L. 101-12, 103 Stat. 16;

11. http://www.acas.org.uk/media/pdf/k/b/Acas_Code_of_ Practice_1_on_disciplinary_and_grievance_proceduresaccessible-version-Jul-2012.pdf;

12. http://www.civilservice.gov.uk/about/resources/civilservice-management-code;

13. http://www.civilservice.gov.uk/about/values/;

14. Code of Practice Discipline and Grievance Procedures, Blackwell, TSO 2009;

15. http://www.civilserviceappealboard.gov.uk/;

16. 5 USC par. 1214, http://www.law.cornell.edu/uscode/ text/5/1214;

17. http://www.mspb.gov/about/jurisdiction.htm;

18. http://www.osc.gov/pppNext1.htm. 